\title{
Apert syndrome
}

INSERM

\section{Source}

INSERM. (1999). Orphanet: an online rare disease and orphan drug data base. Apert syndrome. ORPHA:87

Apert syndrome (AS) is a frequent form of acrocephalosyndactyly (see this term), a group of inherited congenital malformation disorders, characterized by craniosynostosis (see this term), midface hypoplasia, and finger and toe anomalies and/or syndactyly. 